\title{
Evaluation of an Indirect Enzyme-Linked Immunosorbent Assay (ELISA) using Recombinant Toxin for Detection of Antibodies against Pasteurella multocida Toxin
}

\author{
Asuka TAKADA-IWAO ${ }^{1)}$, Takehiko UTO ${ }^{1)}$, Tetsuya MUKAI ${ }^{1)}$, Munenori OKADA ${ }^{1)}$, \\ Satoshi FUTO $^{2)}$ and Isao SHIBATA ${ }^{1)}$ \\ ${ }^{1)}$ Zen-noh Institute of Animal Health, 7 Ohja-machi, Sakura, Chiba 285-0043 and ${ }^{2)}$ Fasmac Co., Ltd., Midorigaoka, Atsugi, Kanagawa \\ 243-0041, Japan
}

(Received 8 August 2006/Accepted 29 January 2007)

ABSTRACT. To facilitate the control of progressive atrophic rhinitis (PAR) of swine caused by toxigenic Pasteurella multocida, an enzymelinked immunosorbent assay (ELISA) and a serum neutralization test (NT) have recently been developed to detect antibodies against the P. multocida dermonecrotic toxin (PmDNT). However, the NT is a cumbersome and time-consuming technique. To overcome these drawbacks, we developed an indirect ELISA, using recombinant PmDNT expressed in Escherichia coli, for the detection of antibodies to PmDNT in serum samples from pigs. The practical usefulness of this ELISA was compared with the NT using serum samples obtained from experimentally infected and naturally infected pigs. In the pigs experimentally inoculated with vaccine including PmDNT toxoid, the ELISA and neutralization antibodies were detected at almost the same time, and a good correlation was demonstrated between both tests $\left(\mathrm{P}<0.01, \mathrm{R}^{2}=0.807\right)$. Therefore, the ELISA can be used to evaluate the immune reaction of pigs after vaccination with $P$. multocida toxoid. In a survey conducted on a field herd with a history of clinical AR, the seropositivity by ELISA in pigs of age $4.5-6$ months was increased even though the NT was negative, and the correlation was low between the results obtained with the two tests $(\mathrm{P}<0.01$, $\mathrm{R}^{2}=0.38$ ). Therefore, the results indicated that this ELISA might be a useful alternative to the NT currently used to detect the antibody to PmDNT after vaccination or infection with P. multocida.

KEY WORDS: ELISA, Pasteurella multocida, recombinant antigen, swine, toxin.

J. Vet. Med. Sci. 69(6): 581-586, 2007

Progressive atrophic rhinitis (PAR) caused by toxigenic Pasteurella multocida (P. multocida) is an important upper respiratory disease in swine. The characteristic lesions of PAR show turbinate bone atrophy, shortening or distortion of the snout and nasal haemorrhage. Moreover, PAR also causes significant economic loss in swine production due to growth retardation [15]. The toxigenic strain of P. multocida types $\mathrm{A}$ and $\mathrm{D}$ synthesize a heat-labile dermonecrotic toxin (DNT) encoded by chromosomal toxA gene. This toxin is the essential virulence factor in the production of the characteristic lesions of PAR [7]. The method for the administration of purified P. multocida DNT (PmDNT) by the intramuscular route was used to evaluate vaccine containing the PmDNT toxoid [10, 19]. Additionally, the PmDNT toxoid is considered an important antigen in vaccines against atrophic rhinitis (AR) $[9,11]$.

Severe forms of PAR can be diagnosed by observing clinical signs, but less severe forms (subclinical forms) must be diagnosed by postmortem examinations or by culturing the causative organism from nasal swabs or by serologic testing, or both. Two methods have been developed in previous studies for PmDNT antibody measurement, an enzymelinked immunosorbent assay (ELISA) [9] and a serum neutralization test (NT) $[2,17]$. Until now, the gene that encodes the DNT, toxA, has been cloned and expressed in Escherichia coli [16]. Hybridization studies using the probes of the tox $A$ gene revealed that the tox $A$ gene is present in all toxigenic $P$. multocida strains but absent in most non-toxigenic strains. On the basis of this knowledge, we developed an ELISA using recombinant toxin for the detection of anti-PmDNT antibodies in pigs. The aim of the work described in this paper was to assess the application of ELISA using recombinant toxin for detecting anti-PmDNT antibodies in pigs with experimental and natural infection, and to compare the sensitivity of the ELISA with the NT.

\section{MATERIALS AND METHODS}

Sera from a specific pathogen-free (SPF) herd: A total of 229 serum samples of growing/finishing pigs and sows were obtained from a SPF herd. This SPF herd has been monitored semiannually by clinical inspections and slaughterhouse examinations performed by veterinarians, and had been considered to be free of AR because of the complete lack of both clinical symptoms and snout lesions indicative of AR. This SPF herd also had no history of P. multocida vaccination.

Experiment 1: Combined B. bronchiseptica/P. multocida infection: The B. bronchiseptica strain S-1 and the toxinproducing type A strain ZF-899 of $P$. multocida employed in a previous study [18] were used as challenge strains. $B$. bronchiseptica was used as the primary invader to colonize $P$. multocida. The cultivation and growth media of the challenge strain was performed as described previously [18]. Four cesarean section-derived, colostrum-deprived, 10week-old pigs produced in our laboratory and maintained in a pathogen-free environment at a controlled air temperature were used. At 10 weeks of age, these four pigs were inoculated intranasally with $1 \mathrm{~m} l$ PBS solution containing $2.3 \times$ $10^{9}$ colony forming units $(\mathrm{CFU}) / \mathrm{m} l$ of $B$. bronchiseptica 
strain S-1 into each nostril, on 5 consecutive days, followed one week later by intranasal inoculation of $1 \mathrm{~m} l$ PBS solution containing $1.7 \times 10^{9} \mathrm{CFU} / \mathrm{m} l$ of toxigenic $P$. multocida strain ZF-899 into each nostril, then slaughtered 4 weeks after inoculation.

Experiment 2: Purified PmDNT inoculation after vaccination: An experimental vaccine containing aluminumhydroxide gel adjuvant, inactivated, purified PmDNT toxoid was used. Forty-eight 4-week-old pigs, transferred from a SPF herd, were divided into two groups. At 4 and 6 weeks of age, the vaccination group received one primary and one booster immunization (a single dose of $1 \mathrm{~m} l$ each time). The pigs in the control group served as unvaccinated controls. At 8 weeks of age, both the vaccinated and control pigs were inoculated intramuscularly with $1 \mathrm{ml}(34.5 \mu \mathrm{g} / \mathrm{m} l)$ of purified PmDNT, then slaughtered 2 weeks after inoculation.

At the end of experiments 1 and 2, all pigs were euthanized by exsanguination after deep anesthesia with sodium pentobarbital (25 mg/kg; Abbot, U.S.A.) and subjected to necropsy. At necropsy, nasal swabs and snouts were collected from all pigs. Nasal swabs were taken from both nostrils of each pig and placed in $1 \mathrm{~m} l$ of sterilized PBS. Isolation of B. bronchiseptica was performed as described previously [18]. The number of CFU/ml of P. multocida was determined by plating serial 10 -fold dilutions on duplicate dextrose starch (DS) agar (Becton, Dickinson and Company, U.S.A.). The snouts were sectioned transversely between the first and second premolar teeth and determined for gross evidence of turbinate atrophy according to the method described by Collins [5]. The turbinate perimeter ratio (TPR), the ratio of the total perimeter of the dorsal and ventral turbinates to the total perimeter of the left and right nasal cavities, was defined as the turbinate perimeter divided by the nostril perimeter. Low values of TPR (under 1.45 ) indicated conchal atrophy. Blood samples were taken every week throughout the experimental period, and all sera were kept at $-20^{\circ} \mathrm{C}$ until assayed.

Sera from a conventional herd: To investigate the immune response in the serum after natural infection, 27 serum samples and nasal swabs were collected from fattening pigs of various ages and sows of various parities in a conventional herd with a history of clinical AR and vaccination. The sows were vaccinated intramuscularly with $2 \mathrm{ml}$ of ART2 (Kaketsuken, Japan) at six to eight and 2 to 4 weeks before expected farrowing. Nasal swabs were used for the bacteriological examination as previously described [18]. The capsular serotypes of $P$. multocida isolates were identified by the acriflavine test and hyaluronidase test $[3$, 18].

Purification of recombinant PmDNT antigen: Purified recombinant PmDNT (RecPmDNT) antigen was prepared from Escherichia coli (E. coli) JM109 transformed with the plasmid vector $\mathrm{pQE} 31$ with a slight modification to the previous report $[12,13,16]$. Briefly, the coding region of the tox $A$ gene was amplified by PCR. The amplified fragment was inserted into the BamHI (5') and SmaI (3') sites of the plasmid pQE31. The recombinant plasmid was used for expression of the recombinant $6 \times$ His-tagged DNT in $E$. coli. The plasmid was introduced into E. coli JM109 by transformation. Expression was induced with $1 \mathrm{mM}$ isopropyl- $\beta$-D-thiogalactopyranoside (IPTG, Takara Bio Inc., Shiga, Japan) at the optical density (OD) 0.6 at a wavelength of $650 \mathrm{~nm}$. After two additional hours for fermentation, the cells induced by IPTG were harvested and then disrupted by sonication. The extract was clarified by centrifugation at $14,000 \mathrm{~g}$ for $30 \mathrm{~min}$. The supernatant was loaded onto a DEAE column and purified by affinity chromatography. Briefly, the supernatant containing RecPmDNT was applied to the DEAE column (TSK gel DEAE-5PW; Tosoh Co., Tokyo, Japan) equilibrated with the same buffer. The supernatant containing RecPmDNT was eluted with a linear gradient of $\mathrm{NaCl}$ concentrations from 0.001 to $0.5 \mathrm{M}$ at $\mathrm{pH} 6.8$. Then the pooled fractions were purified by a $\mathrm{Ni}^{2+}$ chelate absorbent column (HisTrap Amersham Pharmacia Biotech, Uppsala, Sweden) according to the manufacturer's instructions. The fraction containing RecPmDNT was applied to a hydroxyapatite column (TSK gel HA-1000; Tosoh Co., Tokyo Japan). The fraction containing RecPmDNT was eluted with a $500 \mathrm{mM}$ phosphate buffer ( $\mathrm{pH}$ 6.8). The fractions containing RecPmDNT protein were pooled, stored at $-80^{\circ} \mathrm{C}$ and used as the ELISA antigen.

Immunoblotting: SDS-PAGE and Western blotting were performed as described previously [14]. Proteins separated by SDS-PAGE were immunoblotted using 1:20 diluted guinea pig antisera raised against PmDNT.

ELISA procedure: Purified RecPmDNT was diluted to a concentration of $1 \mu \mathrm{g} / \mathrm{m} l$ in $0.05 \mathrm{M}$ carbonate buffer $(\mathrm{pH}$ 9.6), and then $100 \mu l$ of the diluted antigen (positive antigen) was added to each well of the odd-numbered rows of a 96-well flat-bottom plate (Microlon ${ }^{\circledR}$ 600, Greiner, Bio-one $\mathrm{GmbH}$, Frickenhausen, Germany). The diluents used for the recombinant antigen (negative antigen) were then added to each well of the even-numbered rows, and the plate was left at $4^{\circ} \mathrm{C}$ overnight. After excess antigen was removed, each well was blocked with $150 \mu l$ of PBS containing $3 \%$ skim milk at $37^{\circ} \mathrm{C}$ for $2 \mathrm{hr}$. After the plates were washed five times with PBS containing 0.05\% Tween 20 (PBS-T), $100 \mu l$ of each serum sample diluted at 1:100 with PBS-T containing $1 \%$ skim milk was added to each well, and overnight incubation was carried out at $4^{\circ} \mathrm{C}$. The plates were washed with PBS-T, and $100 \mu l$ of horseradish peroxidaseconjugated anti-swine IgG goat serum (Kirkegaard \& Perry Laboratories, MD, U.S.A.) diluted 1:5,000 with PBS was added to each well. The plates were incubated at $37^{\circ} \mathrm{C}$ for 2 hr. The plates were washed, and then $100 \mu l$ of $0.05 \mathrm{M}$ phosphate-citrate buffer ( $\mathrm{pH}$ 5.0) containing 0.04 M of 3, 3', 5, 5'-tetramethylbenzidine (Kirkegaard \& Perry Laboratories, MD, U.S.A.) and $0.02 \%$ hydrogen peroxide was added to each well. After incubation at room temperature for 30 min, the OD at a wavelength of $630 \mathrm{~nm}$ was read with an ELISA reader (MTP-300; Corona Co., Ltd., Tokyo, Japan). The results from the tested sera were expressed in terms of the ELISA values obtained by subtracting the absorbance values for the wells with a negative antigen from those for 
the wells with a positive antigen.

$N T$ : To detect neutralizing antibody, a test was performed with a slight modification of the previously described PmDNT NT [17]. Briefly, purified toxin from strain ZF899 was suitably diluted in a cell culture growth medium (Eagle's minimum essential medium containing $7.5 \%$ fetal calf serum inactivated at $56^{\circ} \mathrm{C}$ for $30 \mathrm{~min}$ and $0.25 \% \mathrm{~L}$ glutamine hydrolysate) to give 8 median tissue culture doses $\left(\mathrm{TCD}_{50}\right) / 0.05 \mathrm{~m} l$ of growth medium. A series of doubling dilutions of sera were added to the toxin and the mixtures were left at $20^{\circ} \mathrm{C}$ for $30 \mathrm{~min}$. Next, $0.05 \mathrm{ml}$ of each mixture was pipetted into a microtiter well (Asahi Techno Glass Corporation, Japan) and $0.05 \mathrm{~m} l$ of an embryonic bovine lung (EBL) cells suspension containing $4.5 \times 10^{5}$ cells $/ \mathrm{ml}$ was added to each well. The plates were incubated under $5 \% \mathrm{CO}_{2}$ at $37^{\circ} \mathrm{C}$ for 5 days, and then the cytopathic effects were examined. The neutralization titer was recorded as the number of dilutions of serum that neutralized toxin. Serum samples with an NT antibody titer (reciprocals) of 1:2 or higher were judged to have shown positive reactions.

Data analysis: Before analysis, the NT antibody titer was transformed into an NT value by using a logarithm $\left(\log _{2}\right)$. The results of the ELISA and NT antibody titer for the vaccinated and control groups were compared using Student's $t$-test, respectively. A probability value of 0.05 was considered statistically significant. Correlation analysis was performed using a linear regression analysis on the ELISA value and NT antibody titer $\left(\log _{2}\right)$.

\section{RESULTS}

Expression of RecPmDNT protein: The expression of RecPmDNT proteins by pQE31 was examined by SDSPAGE and Western blotting using anti-PmDNT guinea pig serum (Fig 1). In this way, the molecular weights of the purified protein were estimated to be approximately 143 $\mathrm{kDa}$, corresponding well with the molecular weight of 147 $\mathrm{kDa}$ calculated from the data for the nucleotide sequence of the PmDNT encoding gene. Similar results were obtained by Western blot analysis using polyclonal antisera against PmDNT.

Cut-off value for ELISA: The cut-off value for the ELISA was determined by using 229 pig sera from a SPF herd (Table 1). The cut-off value was calculated as the mean ELISA value for the serum samples plus 3 times the standard deviation (SD). The mean ELISA value of these sera was 0.057 with an SD of 0.052 . Therefore, an ELISA value of 0.200 (mean ELISA value $+3 \mathrm{SD}=0.213$ ) or higher was designated as positive. When the efficacy of the ELISA was evaluated on 229 serum samples collected from pigs in a SPF herd, which was believed to be $P$. multocida free, a positive reaction by ELISA was obtained with only 4 of 229 samples $(1.7 \%)$, whereas 2 samples $(0.9 \%)$ were seropositive by NT. The specificity for this ELISA was calculated to be $98.3 \%$.

Antibody response following experimental infection with toxigenic P. multocida (Experiment 1): The results of the

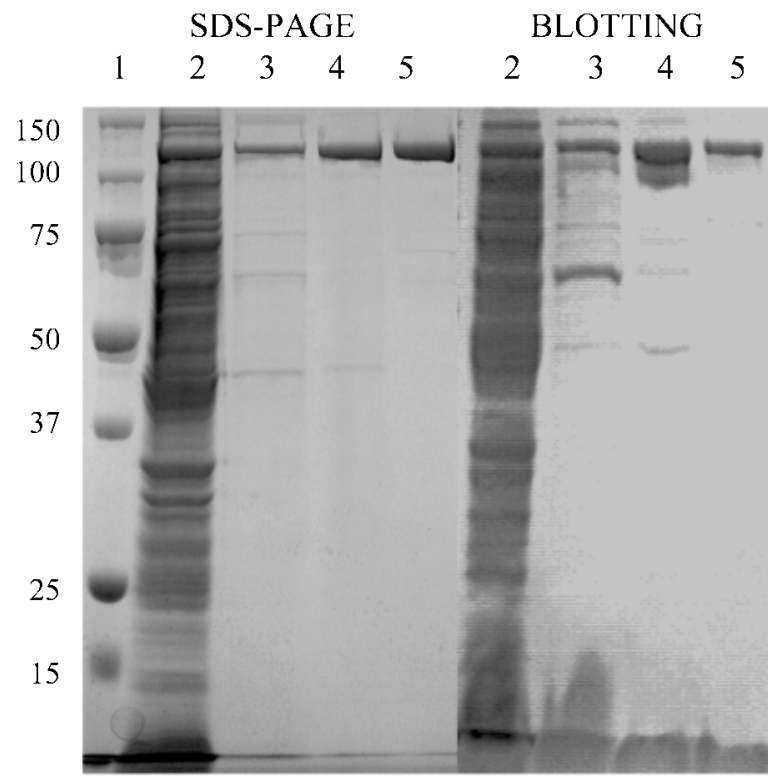

Fig. 1. Purification of RecPmDNT samples were separated by SDS-5 to $20 \%$ PAGE and stained with Comassie brilliant blue and RecPmDNT protein by Western blotting. Lane 1, molecular weight markers; lane 2, cell extract of induced E. coli containing RecPmDNT; lane 3, proteins separated by DEAE column chromatography; lane 4 , proteins separated by $\mathrm{Ni}^{2+}$ column chromatography; lane 5 , protein separated by HA column chromatography. Lanes 2, 3, 4 and 5 were loaded with $143.78,3.63,2.81$ and $2.54 \mu \mathrm{g}$ of protein, respectively. Molecular weight is in $\mathrm{kDa}$.

Table 1. Prevalence of ELISA and NT antibodies in pigs from an SPF herd

\begin{tabular}{lcccccc}
\hline Pigs & \multicolumn{3}{c}{ No. of pigs } & \multicolumn{3}{c}{ No. of pigs positive (\%) } \\
\cline { 3 - 7 } & Age $^{\text {a) }}$ & & \multicolumn{2}{c}{ ELISA } & \multicolumn{2}{c}{ NT } \\
\hline & 1 & 45 & 0 & $(0.0)$ & 0 & $(0.0)$ \\
& 2 & 45 & 0 & $(0.0)$ & 0 & $(0.0)$ \\
Growing/ & 3 & 45 & 0 & $(0.0)$ & 0 & $(0.0)$ \\
finishing & 4 & 16 & 0 & $(0.0)$ & 0 & $(0.0)$ \\
pigs & 5 & 37 & 1 & $(2.7)$ & 0 & $(0.0)$ \\
& 6 & 12 & 0 & $(0.0)$ & 2 & $(16.7)$ \\
\hline Sows & 29 & 3 & $(10.3)$ & 0 & $(0.0)$ \\
\hline Total & 229 & 4 & $(1.7)$ & 2 & $(0.9)$ \\
\hline
\end{tabular}

a) Months of age.

ELISA values, NT antibody titers, recovery of $P$. multocida from nasal swabs, and TPR values are summarized in Table 2. At the time of necropsy, all pigs showed moderate histopathological changes in the turbinate caused by infection with toxigenic $P$. multocida. All pigs were seronegative to PmDNT before infection. Antibodies to PmDNT were first detected from 3 to 4 weeks post $P$. multocida infection by ELISA. However, no antibodies were detected by NT at any time during the experimental period.

Antibody response following experimental inoculation of 
Table 2. Results of ELISA and NT in serum samples from pigs intranasally infected with P. multocida

\begin{tabular}{|c|c|c|c|c|c|c|c|c|c|c|c|c|c|}
\hline \multirow{2}{*}{$\begin{array}{l}\text { Pig } \\
\text { No. }\end{array}$} & \multirow[b]{2}{*}{ Test } & \multicolumn{10}{|c|}{ Weeks post infection ${ }^{\text {a) }}$} & \multicolumn{2}{|c|}{ Postmortem findings } \\
\hline & & 0 & & 1 & & 2 & & 3 & & 4 & & $\begin{array}{l}\text { Recovery of } \\
\text { P.multocida }\end{array}$ & TPR value \\
\hline \multirow[t]{2}{*}{1} & ELISA & $0.025^{\mathrm{b})}$ & $(-)^{\mathrm{c})}$ & 0.032 & $(-)$ & 0.045 & $(-)$ & 0.084 & $(-)$ & 0.112 & $(-)$ & $1.26^{\mathrm{d})}$ & 1.09 \\
\hline & NT & $0^{\mathrm{e})}$ & $(-)$ & 0 & $(-)$ & 0 & $(-)$ & 0 & $(-)$ & 0 & $(-)$ & & \\
\hline \multirow[t]{2}{*}{2} & ELISA & 0.083 & $(-)$ & 0.127 & $(-)$ & 0.090 & $(-)$ & 0.082 & $(-)$ & 0.102 & $(-)$ & 0.8 & 0.75 \\
\hline & NT & 0 & $(-)$ & 0 & $(-)$ & 0 & $(-)$ & 0 & $(-)$ & 0 & $(-)$ & & \\
\hline \multirow[t]{2}{*}{3} & ELISA & 0.058 & $(-)$ & 0.026 & $(-)$ & 0.055 & $(-)$ & 0.104 & $(-)$ & 0.205 & $(+)$ & 1.3 & 1.30 \\
\hline & NT & 0 & $(-)$ & 0 & $(-)$ & 0 & $(-)$ & 0 & $(-)$ & 0 & $(-)$ & & \\
\hline \multirow[t]{2}{*}{4} & ELISA & 0.030 & $(-)$ & 0.059 & $(-)$ & 0.114 & $(-)$ & 0.212 & $(+)$ & 0.593 & $(+)$ & 1.3 & 1.17 \\
\hline & NT & 0 & $(-)$ & 0 & $(-)$ & 0 & $(-)$ & 0 & $(-)$ & 0 & $(-)$ & & \\
\hline
\end{tabular}

a) Weeks post $P$. multocida infection.

b) ELISA value equal to or greater than 0.2 was judged positive.

c) Judgement +: Positive -: Negative.

d) $10^{\mathrm{n}} \mathrm{CFU} / \mathrm{m} l$.

e) NT value $\left(\log _{2}\right)$ of 1 or greater was positive.

Table 3. Results of ELISA and NT in serum samples from pigs inoculated with vaccine containing PmDNT toxoid

\begin{tabular}{|c|c|c|c|c|c|c|c|c|c|c|c|c|c|c|c|}
\hline \multirow{3}{*}{ Test } & & \multicolumn{14}{|c|}{ Weeks post vaccination } \\
\hline & & \multicolumn{2}{|c|}{0} & \multicolumn{2}{|c|}{1} & \multicolumn{2}{|c|}{2} & \multicolumn{2}{|c|}{3} & \multicolumn{2}{|c|}{4} & \multicolumn{2}{|r|}{5} & \multicolumn{2}{|r|}{6} \\
\hline & & $\mathrm{V}^{\mathrm{a})}$ & $C^{\text {b) }}$ & V & $\mathrm{C}$ & V & $\mathrm{C}$ & $\mathrm{V}$ & $\mathrm{C}$ & $\mathrm{V}$ & $\mathrm{C}$ & $\mathrm{V}$ & $\mathrm{C}$ & $\mathrm{V}$ & $\mathrm{C}$ \\
\hline \multirow[t]{6}{*}{ ELISA } & Mean & 0.027 & 0.025 & 0.056 & 0.025 & 0.302 & 0.034 & 0.511 & 0.027 & 0.565 & 0.029 & 0.839 & 0.035 & 0.702 & 0.041 \\
\hline & SD & $(0.019)$ & $(0.019)$ & $(0.100)$ & $(0.031)$ & $(0.319)$ & $(0.057)$ & $(0.360)$ & $(0.036)$ & $(0.347)$ & $(0.027)$ & $(0.298)$ & $(0.027)$ & $(0.295)$ & $(0.051)$ \\
\hline & $\operatorname{Max}^{\mathrm{c})}$ & 0.061 & 0.072 & 0.468 & 0.128 & 0.949 & 0.114 & 1.195 & 0.101 & 1.167 & 0.116 & 1.312 & 0.093 & 1.226 & 0.171 \\
\hline & $\operatorname{Min}^{\mathrm{d})}$ & 0.01 & -0.002 & -0.05 & -0.019 & 0.016 & -0.002 & 0.071 & -0.007 & 0.037 & -0.001 & 0.35 & -0.004 & 0.132 & -0.003 \\
\hline & $\mathrm{P}^{\mathrm{e})}$ & 0 & 0 & 2 & 0 & 11 & 0 & 18 & 0 & 18 & 0 & 24 & 0 & 23 & 0 \\
\hline & $\mathrm{N}^{\mathrm{f})}$ & 24 & 24 & 22 & 24 & 13 & 24 & 6 & 24 & 6 & 24 & 0 & 24 & 1 & 24 \\
\hline \multirow[t]{6}{*}{ NT } & Mean & 0.04 & 0.00 & 0.48 & 0.00 & 1.60 & 0.00 & 2.27 & 0.00 & 3.13 & 0.00 & 3.85 & 0.00 & 3.75 & 0.00 \\
\hline & SD & $(0.282)$ & (0) & $(0)$ & (0) & (1.428) & (0) & $(1.725)$ & (0) & (1.756) & (0) & (1.398) & (0) & (1.755) & (0) \\
\hline & Max & 1 & 0 & 0 & 0 & 4 & 0 & 5 & 0 & 6 & 0 & 6 & 0 & 9 & 0 \\
\hline & Min & 0 & 0 & 0 & 0 & 0 & 0 & 0 & 0 & 0 & 0 & 1 & 0 & 0 & 0 \\
\hline & $\mathrm{P}$ & 0 & 0 & 0 & 0 & 9 & 0 & 18 & 0 & 19 & 0 & 24 & 0 & 23 & 0 \\
\hline & $\mathrm{N}$ & 24 & 24 & 24 & 24 & 15 & 24 & 6 & 24 & 5 & 24 & 0 & 24 & 1 & 24 \\
\hline
\end{tabular}

At 4 and 6 weeks of age, the vaccination group $(n=24)$ received a primary and booster immunization. The pigs in the control group ( $\mathrm{n}=24)$ served as unvaccinated control. All pigs were challenge-exposed intramuscularly with purified PmDNT at 8 weeks of age. An ELISA value of 0.2 or greater was judged positive. NT value $\left(\log _{2}\right)$ of 1 or greater was positive.
a) Vaccination group.
b) Control group.
c) Maximum.
d) Minimum.
e) Number of positive.
f) Number of negative.

purified PmDNT after vaccination (Experiment 2): At the time of necropsy, the mean of the TPR values was significantly higher in the vaccinated group (1.36) than in the unvaccinated control group (0.62) $(\mathrm{P}<0.01)$. The comparative results using the two tests on the sequential sera from the forty-eight pigs are shown in Table 3 . The pattern of response in both methods was similar. All serum samples taken from the pigs in both groups before vaccination were negative both by ELISA and by NT. At the time of 2 weeks post vaccination, the mean ELISA values in the vaccinated group increased, and the mean ELISA value of the vaccinated group (0.319) was significantly higher than that of the control group (0.057) $(\mathrm{P}<0.01)$. However, thirteen of the 24 samples were still negative. In the control pigs, no antibodies were detected throughout the experimental period using ELISA. The mean NT antibody titer in the vaccinated group was significantly higher than in the control group at the time of 2 weeks post vaccination $(\mathrm{P}<0.05)$ and after 3 weeks post vaccination $(\mathrm{P}<0.01)$. In the control pigs, no antibodies were detected throughout the experimental period using NT. There were significant linear relationships between the results obtained by the ELISA and NT in Experiment 2 $\left(\mathrm{P}<0.01, \mathrm{R}^{2}=0.807\right)$.

Antibody response of pigs from a conventional herd: The results of 27 samples of growing/finishing pigs with various ages, gilts, and sows collected from a conventional herd are 
Table 4. Results of ELISA and NT, isolation from nasal swabs, and clinical signs of PAR of pigs in a conventional herd

\begin{tabular}{|c|c|c|c|c|c|c|c|c|c|c|}
\hline \multirow[t]{2}{*}{ Pigs } & \multirow[b]{2}{*}{$\operatorname{Age}^{\mathrm{a})}$} & \multirow[t]{2}{*}{ Vaccination } & \multirow{2}{*}{$\begin{array}{l}\text { No. of } \\
\text { pigs }\end{array}$} & \multicolumn{2}{|c|}{ ELISA positive } & \multicolumn{2}{|c|}{ NT positive } & \multirow{2}{*}{$\begin{array}{l}\text { Clinical } \\
\text { sign }\end{array}$} & \multicolumn{2}{|c|}{ Isolation of P.multocida } \\
\hline & & & & No. & $($ Mean $\pm \mathrm{SD})$ & No. & $($ Mean $\pm \mathrm{SD})$ & & Type A & Type D \\
\hline Gilts & 8 & 1 time & 3 & 3 & $(0.962 \pm 0.23)$ & 3 & $(6.33 \pm 5.03)$ & 0 & 2 & 0 \\
\hline Sows & 19 & 2 times & 3 & 3 & $(0.966 \pm 0.46)$ & 3 & $(9.67 \pm 1.15)$ & 0 & 0 & 0 \\
\hline \multirow{7}{*}{$\begin{array}{l}\text { Growing/ } \\
\text { finishing } \\
\text { pigs }\end{array}$} & 1 & - & 3 & 3 & $(0.372 \pm 0.55)$ & 3 & $(7.11 \pm 2.31)$ & 0 & 0 & 0 \\
\hline & 1.5 & - & 3 & 2 & $(0.347 \pm 0.29)$ & 2 & $(3.56 \pm 4)$ & 0 & 1 & 2 \\
\hline & 2 & - & 3 & 0 & $(0.044 \pm 0.03)$ & 3 & $(3.63 \pm 0.58)$ & 0 & 0 & 0 \\
\hline & 3 & - & 3 & 0 & $(0.110 \pm 0.02)$ & 1 & $(1.45 \pm 1.16)$ & 0 & 0 & 0 \\
\hline & 4 & - & 3 & 3 & $(0.327 \pm 0.03)$ & 0 & $(0 \pm 0)$ & $3^{\text {b) }}$ & 0 & 0 \\
\hline & 5 & - & 3 & 3 & $(0.482 \pm 0.21)$ & 0 & $(0 \pm 0)$ & 3 & 1 & 2 \\
\hline & 6.5 & - & 3 & 3 & $(0.451 \pm 0.21)$ & 0 & $(0 \pm 0)$ & 3 & 2 & 1 \\
\hline
\end{tabular}

a) Months of age.

b) Pigs at 4 to 6.5 months of age had clinical sign of AR such as distortion and/or shortning of the snout.

shown in Table 4. At the age of 4 to 6.5 months, clinical signs of PAR (sneezing, deviation of the snouts, retarded growth) were recorded, and P. multocida (not examined for toxigenicity) were isolated from the nasal swabs taken from the pigs at various stages. B. bronchiseptica could not be isolated at any stage from nasal swabs. High antibody titers by ELISA and NT were detected in the sera of all gilts, sows and pigs at the age of one month. The ELISA antibody titers declined between weaning and 2 months of age. The seroconversions occurred at the age of 4 months by ELISA, whereas not by NT. There was a significant linear relationship $(\mathrm{P}<0.01)$ between the results of the ELISA and NT in sera from a conventional herd, although the strength of the association was very weak $\left(\mathrm{R}^{2}=0.38\right)$.

\section{DISCUSSION}

Numerus assays have been developed to evaluate the antibody against PmDNT in the sera of pigs. In the present study, ELISA using recombinant PmDNT antigen was evaluated for the detection of antibodies to PmDNT in serum samples from pigs experimentally infected and reared under field conditions.

The results of the sera from the SPF herd indicated that the ELISA is suitable for laboratory use in health surveillance programs based on the screening of serum samples for antibodies to PmDNT in SPF herds. However, the data indicated that more false positive reactions could be expressed when the ELISA was used on sera from sows. This is probably due to cross-reacting serum antibodies developing with the age of the pig.

There was a good correlation between the results by the ELISA and NT on the sera from pigs experimentally inoculated with purified PmDNT after vaccination (Experiment 2). The ELISA antibody titers increased after booster immunization, and these correlated with the NT antibody titers. This pattern of response is consistent with that previously reported [18]. This result indicates that the ELISA could be used to detect the antibody to vaccine PmDNT. Therefore, it might be possible to use the ELISA to examine the immune condition of pigs after they have received the vaccination of PmDNT toxoid.

To study the practical usefulness of this ELISA, serum samples collected from a conventional herd were examined by ELISA and NT. ELISA and NT could clearly detect the antibodies in the sera of the vaccinated pigs and maternal antibodies in the sera of weaned pigs, and might be used to estimate the decay of those antibodies, with significant relationships between both methods.

However, all the sera from the pigs at 4 to 6.5 months of age were seropositive in the ELISA, even though the NT was negative. At age 4 to 6.5 months, the ELISA values increased, and the onset of clinical signs in the pigs was recognized. These results indicated that the antibodies detected by the ELISA were produced by the infection. Moreover, this result suggested that the ELISA showed early seroconversion rates in naturally infected pigs. The results of the ELISA for the conventional herd were considered to indicate the temporal relationship between fading maternal immunity and subsequent infection with P. multocida, and the relationship between seroconversion and the onset of clinical signs in pigs. The greater sensitivity of the ELISA was likely attributed to the use of a highly purified recombinant antigen. Moreover, whereas the EBL neutralization assay can be used to determine the ability of sera to reduce the cytopathic effect of PmDNT, the ELISA should be used to determine the concentration of PmDNT antibodies in the serum samples.

It was shown that the NT antibody titers in the pigs at the early stage of infection were very low. This pattern is consistent with a previous report by Chanter [4], which described how the combined infection of $P$. multocida and B. bronchiseptica failed to produce humoral antibodies to the osteolytic toxin of P. multocida until 39 days post inoculation. Currently, it was shown that naturally affected pigs lack toxin-neutralizing antibodies or show a late and hardly detectable humoral response [8].

In general, serological studies have shown that the immune responses to PmDNT of pigs in herds with PAR were sporadic and weak or immeasurable, whereas vaccination with PmDNT toxoid could induce high and regular antibody titers to PmDNT. The low sensitivity of competitive 
ELISA has been reported in the sera from a conventional herd which were not vaccinated with a vaccine containing PmDNT. Only $5 \%$ of the pigs in this herd seroconverted, despite $28 \%$ having a visible distortion of the snout, and an explanation for this discrepancy between snout distortion and serology may be low sensitivity $(23 \%)$ of the competitive ELISA [1]. Measuring serum antibodies against PmDNT might not be the best method to identify pigs that are subclinically infected with toxigenic $P$. multocida. The final diagnosis of PAR will still rely on the isolation of toxigenic $P$. multocida and evaluation of postmortem examinations.

The NT is a cumbersome and time-consuming technique, one that is by no means optimal for a large number of diagnostic samples. Compared with NT, the advantages of the ELISA are simplicity, speed, efficiency, and the low cost of the procedure, as a cell culture is not needed. The laboratory diagnosis of PmDNT antibodies by the ELISA takes two days from the receipt of the swine serum, and one laboratory worker can perform it for several hundred samples, without the need for cell culture. Thus, many more samples can be evaluated at a time than with NT.

In conclusion, the ELISA using recombinant toxin described here is highly specific and sensitive in detecting antibodies against PmDNT. On the basis of the data presented here, further investigation is needed to determine the time elapsed from natural infection to seroconversion using this ELISA.

\section{REFERENCES}

1. Andreasen, M., Nielsen, J. P., Baekbo, P., Willeberg, P. and Botner, A. 2000. A longitudinal study of serological patterns of respiratory infections in nine infected Danish swine herds. Prev. Vet. Med. 45: 221-235.

2. Beckmann, G. and Schöss, P. 1990. Neutralizing activity against Pasteurella multocida toxin in sera of pigs with atrophic rhinitis. p. 50. In: The Scientific Committee of the IPVS Congress (eds), Proceeding of the International Congress of the Pig Veterinary Society, Lausanne, International Pig Veterinary Society, Lausanne.

3. Carter, G. R. and Subronto, P. 1973. Identification of type D strains of Pasteurella multocida with acriflavine. Am. J. Vet. Res. 34: 293-294.

4. Chanter, N., Magyar, T. and Rutter, J. M. 1989. Interactions between Bordetella bronchiseptica and toxigenic Pasteurella multocida in atrophic rhinitis of pigs. Res. Vet. Sci. 47: 48-53.

5. Collins, M. T., Backstrom, L. R. and Brim, T. A. 1989. Turbinate perimeter ratio as an indicator of conchal atrophy for diagnosis of atrophic rhinitis in pigs. Am. J. Vet. Res. 50: 421-424.

6. Djordjevic, S. P., Eamens, G. J., Ha, H., Walker, M. J. and Chin, J. C. 1998. Demonstration that Australian Pasteurella multocida isolates from sporadic outbreaks of porcine pneumo- nia are non-toxigenic (toxA-) and display heterogeneous DNA restriction endonuclease profiles compared with toxigenic isolates from herds with progressive atrophic rhinitis. J. Med. Microbiol. 47: 679-688.

7. Dominick, M. A. and Rimler, R. B. 1986. Turbinate atrophy in gnotobiotic pigs intranasally inoculated with protein toxin isolated from type D Pasteurella multocida. Am. J. Vet. Res. 47: $1532-1536$.

8. Foged, N.T. 1992. Pasteurella multocida toxin. The characterisation of the toxin and its significance in the diagnosis and prevention of progressive atrophic rhinitis in pigs. APMIS (Suppl.) 25: $1-56$.

9. Foged, N. T., Nielsen, J. P. and Jorsal, S. E. 1989. Protection against progressive atrophic rhinitis by vaccination with Pasteurella multocida toxin purified by monoclonal antibodies. Vet. Rec. 125: 7-11.

10. Frymus, T., Müller, E., Franz, B. and Petzoldt, K. 1989. Protection by toxoid-induced antibody of gnotobiotic piglets challenged with the dermonecrotic toxin of Pasteurella multocida. J. Vet. Med. B. 36: 674-680.

11. Kobish, M. and Pennings, A. 1989. An evaluation in pigs of Nobi-Vac AR and an experimental atrophic rhinitis vaccine containing P. multocida DNT-toxoid and B. bronchiseptica. Vet. Rec. 124: 57-61.

12. Lax, A. J. and Chanter, N. 1990. Cloning of the toxin gene from Pasteurella multocida and its role in atrophic rhinitis. $J$. Gen. Microbiol. 136: 81-87.

13. Nielsen, J. P., Foged, N. T., Sorensen, V., Barfod, K., Bording, A. and Petersen, S. K. 1991. Vaccination against progressive atrophic rhinitis with a recombinant Pasteurella multocida toxin derivative. Can. J. Vet. Res. 55: 128-138.

14. Okada, M., Asai, T., Futo, S., Mori, Y., Mukai, T., Yazawa, S., Uto, T., Shibata, I. and Sato, S. 2005. Serological diagnosis of enzootic pneumonia of swine by a double-sandwich enzymelinked immunosorbent assay using a monoclonal antibody and recombinant antigen (P46) of Mycoplasma hyopneumoniae. Vet. Microbiol. 105: 251-259.

15. Pedersen, K. B., Nielsen, J. P., Foged, N. T., Elling, F., Nielsen, N. C. and Willeberg, P. 1988. Atrophic rhinitis in pigs: proposal for a revised definition. Vet. Rec. 122: 190-191.

16. Petersen, S. K. and Foged, N. T. 1989. Cloning and expression of the Pasteurela multocida toxin gene, toxA, in Escherichia coli. Infect. Immun. 57: 3907-3913.

17. Rutter, J. M. and Luther, P. D. 1984. Cell culture assay for toxigenic Pasteurella multocida toxin from atrophic rhinitis of pigs. Vet. Rec. 114: 393-396.

18. Sakano, T., Okada, M., Taneda, A., Mukai, T. and Sato, S. 1997. Effect of Bordetella bronchiseptica and serotype D Pasteurella multocida bacterin-toxoid on the occurrence of atrophic rhinitis after experimental infection with $B$. bronchiseptica and toxigenic type A P. multocida. J. Vet. Med. Sci. 59: 55-57.

19. To, H., Someno, S. and Nagai, S. 2005. Development of a genetically modified nontoxigenic Pasteurella multocida toxin as a candidate for use in vaccines against progressive atrophic rhinitis in pigs. Am. J. Vet. Res. 66: 113-118. 